\title{
The Current Researches on T Follicular Helper Cells and Associated Diseases
}

\author{
Jianwei Zhou ${ }^{1}$, Cui Kong ${ }^{2}$
}

\begin{abstract}
$T$ follicular helper (Tfh) cell is a new subpopulation of $\mathrm{CD}^{+} T$ cell family, whose differentiation is affected by Bcl-6, Blimp-1, STAT3, STAT5 and so on, and it could affect or decide the development of other subsets of $\mathrm{CD}^{+}{ }^{+}$T cells. The important function of Tfh cell is to help $B$ cell mediate humoral immunity, many researches have proved that Tfh cells participate in the development of autoimmune disease, immunodeficient disease, tumor and infectious diseases.
\end{abstract}

Key words: T follicular helper, Differentiation, B cell, Associated diseases

J Enam Med Col 2012; 2(2): 85-91

\section{Introduction}

Traditionally $\mathrm{Th} 2$ is recognized as the main factor which helps B cells to mediate humoral immunity. Recently a new T-cell subgroup named $\mathrm{T}$ follicular helper (Tfh) cells, which express CXCR5 (chemokine receptor type 5) and ICOS (inducible co-stimulator), are taken as the key power to regulate B cell activity. This article reviews on the research about Tfh cells and the associated diseases.

\section{Differentiation of $\mathrm{Tfh}$ cell}

Tfh cells are generated from $\mathrm{CD}^{+}$T-cell and transcription repressor B-cell lymphoma 6 (Bcl-6) is one of the important transfer factor ${ }^{1,2}$ and IL-21 is the key cytokine which causes differentiation and development of Tfh cell. ${ }^{3}$ Danelle ${ }^{4}$ created the mice models deficient of IL- 6 and IL-21 respectively, and found that only deficiency of IL-6 or IL-21 could not affect the development of $\mathrm{Tfh}$ cells, at the time of exiting both could be functional. IL-27 also affected Tfh cell because of enhancing the expression of IL21. ${ }^{5}$ Fazilleau $^{6}$ took B10 and BR mice as the models of CI-EK limiting the response of $\mathrm{Tfh}$ cell, and proved that the combination ability of TCR with pMHCII and TCR signal intensity could effect Tfh cell differentiation. Moreover, the amount of Tfh cell would increase under the stimulation of adjuvant. Musculoaponeurotic fibrosarcoma (Maf) could induce CXCR5 expression, co-expression of Bcl-6 and Maf revealed that Bcl-6 and Maf cooperate in the induction of CXCR4, PD-1, and ICOS. These findings reveal that $\mathrm{Bcl}-6$ and Maf collaborate to orchestrate a suite of genes that define core characteristics of human Tfh cell biology. ${ }^{7}$

B lymphocyte-induced maturation protein 1 (Blimp1) is the suppressive factor to Bcl-6; it could effect differentiation and development of Tfh cell through directly inhibiting expression of $\mathrm{B}$ cells and $\mathrm{T}$ cells. Reversely, Blimp-1 also could be inhibited by Bcl-6, so balance of the both molecules is the essential aspect for Tfh cell. ${ }^{8}$ Presently, Scholar Kitano 9 found that the level of Bcl-6 would decrease after proliferation for several weeks, and could avoid over-proliferation of Tfh cell, and probably Blimp-1 was the important inhibiting protein.

1. Clinic Laboratory, Affiliated Hospital of Jining Medical College, Jining 272029, Shandong province, China

2. Cardiovascular Medicine Department, Affiliated Hospital of Jining Medical College, Jining 272029, Shandong Province, China

Correspondence Jian-wei Zhou, Email: zhoujianwei2009@163.com,Phone: +86-537-2903223 
Transcription repressor STAT (Signal transducer \& activator of transcription) family plays an important role in Tfh cell differentiation. $\mathrm{Ma}^{10}$ examined $\mathrm{CD}^{+}$ $\mathrm{T}$ cells of patients deficient in IL-12R $\beta 1$, TYK2 (Tyrosine kinase 2) and STAT3 and explored the pathways involved in human Tfh cell differentiation, and found that mutations in IL-12R $\beta 1$, TYK2, or STAT3 compromised IL-12-induced expression of IL-21 by human $\mathrm{CD} 4^{+} \mathrm{T}$ cells. Defective expression of IL-2 1 by STAT3-deficient $\mathrm{CD}^{+}{ }^{+} \mathrm{T}$ cells resulted in diminished B-cell activity in vitro. Especially, mutations in STAT3 also reduced generation of Tfh cell in vivo. Constitutive STAT5 signaling in activated $\mathrm{CD}^{+} \mathrm{T}$ cells selectively blocked $\mathrm{Tfh}$ cell differentiation and GCs (Germinal centers). STAT5 could regulate $\mathrm{Tfh}$ cell differentiation and the function is dependent on Blimp-1. There was a report that STAT5 signaling failed to inhibit Tfh cell differentiation in the absence of the transcription factor Blimp-1, and a direct repressor of Bcl-6 expression. Constitutively, STAT5 regulated the expression of Tfh cell suppressor factor Blimp-1, STAT5 deficiency impaired Blimp-1 expression and resulted in elevated expression of Tfh specific genes. Blimp-1 over-expression inhibited $\mathrm{Tfh}$ cell gene expression in STAT5-deficient T cells. ${ }^{11,12}$

The immunoglobulin-like glycoprotein CD226 is involved in the differentiation of naïve $\mathrm{CD} 4^{+} \mathrm{T}$ cells into effector cells. CD155 that is widely overexpressed on tumor cells, was identified as a counterreceptor of CD226 rendering many cancer cells sensitive to NK driven elimination. However, CD155 was also assigned to play role in the establishment of Tfh cells in the small intestine and the final maturation of $\mathrm{CD} 8$ positive thymocytes, the mice lacking CD226 are distinguished by virtually identical phenotypes as already reported for CD155 deficient mice: a paucity of follicular helper $\mathrm{T}$ cells in Peyer's patches and of terminally matured $\mathrm{CD} 8^{+} \mathrm{T}$ cells in thymus. ${ }^{13}$

CD80 is one of the few markers shared by human and murine memory B cells. There is an article which reported that $\mathrm{CD} 80^{-/-}$mice had fewer Tfh cells compared with that of controls, and residual Tfh cells failed to mature, with decreased ICOS and PD-1 expression and decreased synthesis of IL-21 mRNA. Mixed bone marrow chimeras demonstrated a B cellintrinsic requirement for $\mathrm{CD} 80$ expression for normal Tfh cell and plasma cell development. ${ }^{14}$
Additionally, IL-2 is a critical factor that regulates successful Tfh and B cell responses in vivo and regulates Tfh cell development. ${ }^{11,15}$

\section{Relationship between $\mathrm{Tfh}$ cell and other T-cell subgroups}

As researches showed ${ }^{16}$, in the Tfh cells of mice, Bcl-6 could inhibit activity of GATA-3 and T-bet, both were inhibited when Bcl-6 was overexpressed, and the amount of Th1, Th2, Th17 decreased accordingly; while these subpopulation increased when Bcl-6 was insufficient. So Bcl-6 downregulated the differentiation and function of $\mathrm{T}$ cell subpopulation except for Tfh cells. Nakayamada ${ }^{17}$ showed Tfh and Th1 cells share a transitional stage through the signal mediated by STAT4, which promotes both phenotypes, on the other hand, STAT4 could induce the transcription factor T-bet, while Tbet could repress Bcl-6 and other markers of Tfh cells, and constrained Tfh cell expansion and consequent GCs formation and antibody production, while T-bet could repress the functionalities of $\mathrm{Tfh}$ cell, and promote Th1 cell differentiation.

Another study reported that, during viral infection, most of the $\mathrm{CD}^{+} \mathrm{T}$ cells did not differentiate into Th1 cell but Tfh cell, this change will be beneficial for virus infection. ${ }^{18}$ Interestingly, Tfh cell affected other $\mathrm{T}$ cell subgroup not only by inhibiting their secretion of cytokines, but also by enhancing some cytokines which were secreted by other $\mathrm{T}$ subpopulations generally, to replace their secretory function. 19,20

Linterman $^{21}$ described a population of Foxp $3^{+}$ Blimp $-1^{+} \mathrm{CD} 4^{+} \mathrm{T}$ cells constituting $10-25 \%$ of the CXCR5 ${ }^{\text {high }} \mathrm{PD}-1^{\text {high }} \mathrm{CD} 4^{+} \mathrm{T}$ cells found in the GCs after immunization with protein antigens, which were named as follicular regulatory $\mathrm{T}$ (Tfr) cells, and shared phenotypic characteristics with Tfh cell and conventional Foxp $3^{+}$regulatory $\mathrm{T}$ (Treg) cells, but still they are distinct from both. Similar to Tfh cell, Tfr cell development depends on Bcl-6, signaling lymphocyte activation molecule associated protein (SLAM-associated protein [SAP]), CD28 and B cells; however, Tfr cells originate from thymusderived Foxp $3^{+}$precursors, not Tfh cells. Tfr cells are suppressive in vitro and limit $\mathrm{Tfh}$ cell and germinal center B cell numbers in vivo. In the absence of Tfr cells, an outgrowth of non-antigen-specific B cells in 
GC leads to fewer antigen-specific cells. Thus, the Tfh differentiation pathway is coopted by Treg cells (regulatory $\mathrm{T}$ cells) to control the germinal center response.

Besides, in the T cell families, Tfh cell is like Th17 cell, e.g., they all secrete IL-17, IL-21 and express ICOS, and their development depends on IL-6, IL21, c-Maf and STAT3. However, Tfh cell does not secrete IL-17A, IL-17F and IL-22, the cytokines are actually secreted by Th17 cell, and its differentiation does not depend on ROR $\gamma t$ (receptor related orphan receptor $\gamma \mathrm{t})$ and TGF- $\beta$.

\section{The mechanism of $\mathbf{T}$ fh cell helping $B$ cell}

IL-21 not only improves the differentiation of Tfh cell, but also affects the function of Tfh cells on B cells. IL-21 could induce human B cells to produce large amount of $\operatorname{IgM}, \operatorname{IgG}$ and $\operatorname{IgA}$ in some organs (tonsil, spleen or Peyer's patches) ${ }^{22}$, this is because IL-21R is clearly expressed on plasma cell from the human tonsil, the lymph node, and the spleen (secondary lymphoid organs, SLO); this effect was impaired when endogenous IL-21 production was blocked. $^{23}$

Inducible co-stimulator (ICOS) is the member of CD28 families, its ligand (ICOSL) mainly is expressed on the antigen presenting cells (APCs). Tfh cell secretes ICOS, B cells highly express ICOSL, their combination could induce expression of Bcl- $6^{24}$; thus, Tfh cells improve the quantity of IL-21, IL-4, IL-10, which enhance humoral immunity mediated by B cells. ${ }^{25,26}$

Linterman $^{27}$ found a kind of cells, phenotype of which were $\mathrm{CD}^{+}{ }^{+} \mathrm{CD} 3^{-}$, so called lymph tissue stimulating cells, could express OX40L and CD30L, which could combine with OX40 and CD30 on the surface of $\mathrm{Tfh}$ respectively, the combination promotes level of CXCR5 and co-location of Tfh cells in the GC.

There is a subset of Treg cells expressing CXCR5 and Bcl-6 that localize to the germinal centers in mice and humans. These $\mathrm{CXCR} 5^{+} \mathrm{Bcl}-6^{+}$Treg cells are absent in the thymus, but can be generated de novo from $\mathrm{CXCR}^{-} \mathrm{Foxp}^{+}$natural Treg precursors. A lack of $\mathrm{CXCR}^{+}$Treg cells leads to greater germinal center reactions including germinal center B cells, affinity maturation of antibodies and the differentiation of plasma cells. These results unveil a Bcl-6-CXCR5 axis in Treg cells that drives the development of follicular regulatory $\mathrm{Tfr}$ cells that function to inhibit the germinal center reactions. ${ }^{28}$

Conserved noncoding sequence 2 (CNS2) is an essential enhancer element for IL-4 expression in Tfh, but not in Th2 cells. Mice with a CNS2 deletion had a reduction in IgG1 and IgE production and in IL-4 expression in Tfh cells. Tracking of CNS2 activity via a GFP reporter mouse demonstrated that CNS2-active cells expressed several markers of Tfh cells: CXCR5, PD-1, and ICOS; the transcriptional master regulator Bcl-6; the cytokines IL-21 and IL-4. These indicate that CNS2 is an essential enhancer element required for IL-4 expression in Tfh cells controlling humoral immunity. 29,30

\section{Tfh and associated diseases}

There are two groups of factors that maintain $\mathrm{Tfh}$ cell functionality ${ }^{31-33}$, one is promoter, such as IL21, IL-6, IL-10, IL-27, Bcl-6, OX40, CXCR3, ICOS; the other is inhibitor, e.g. Blimp-1, PD-1, Treg, DC and PC. Any disorders in these factors causes autoimmune disease, immunodeficient disease, tumor and infectious disease.

\subsection{Autoimmune diseases}

\subsubsection{Systemic lupus erythematosus}

Nurieva $^{34}$ treated C57BL/6 mouse with N-ethyl-Nnitrosourea and successfully created Sanroque model with systemic lupus erythematosus (SLE). In the progress of SLE formation, roquein plays an important role. Roquein is a negative mediative protein for Tfh cell, when mutation happened, the function of inhibiting ICOS weakend, and large mount of Tfh cells accumulated in GCs, then the autoreaction mediated by B cells enhanced, resulting in autoimmune diseases, such as SLE. ${ }^{35,36}$

\subsubsection{Rheumatoid arthritis}

Some scholars created mice models with collagen induce arthritis (CIA), and then they used monoantibody specific to ICOS to block ICOS signal pathway. As a result, the inflammatory symptom remitted and the production of abnormal GC in synovial membrane decreased. These showed that Tfh cell is the important element for the generation of RA. ${ }^{37}$ 


\subsubsection{Autoimmunological hepatitis}

In the species of NTx-PD ${ }^{-/-}$mice models, there were lots of GCs, while Tfh existed in $\mathrm{B}$ regions, and could transfer into liver, high quantity of IL-21 secreted by them could activate $\mathrm{CD} 8^{+} \mathrm{T}$ cells which caused liver damage, resulting in autoimmunological hepatitis (AIH). However, inhibition of CCR6 and CCL20 of Tfh and $\mathrm{CD}^{+} \mathrm{T}$ cell could decrease the recurrence of $\mathrm{AIH} .{ }^{38}$

\subsubsection{Autoimmune thyroid disease}

$\mathrm{Zhu}^{39}$ assessed circulating Tfh cells of sixty-five patients with autoimmune thyroid disease (AITD) by flow cytometry, analyzed the correlation between the percentages of $\mathrm{CD} 4^{+} \mathrm{CXCR} 5^{+} \mathrm{ICOS}^{\text {high }} \mathrm{T}$ cells and the levels of autoantibodies or hormones. Increased percentages of circulating Tfh cells in AITD patients were detected, and a positive correlation between the percentages of circulating $\mathrm{Tfh}$ cells and the serum concentrations of anti-TSH receptor$\mathrm{Ab} /$ thyroperoxidase-Ab/thyroglobulin-Ab was confirmed. A positive or modest relationship between the percentages of circulating Tfh cells and serum free T3 or free T4 was revealed in Grave's disease patients. After treatment, the percentage of circulating Tfh cells decreased in some Grave's disease patients.

\subsubsection{Type 1 diabetes}

Type 1 diabetes is an autoimmune disease caused by islet-reactive $\mathrm{T}$ cells which destroy insulin-producing $\beta$-cells. Diego ${ }^{40}$ measured islet-specific $\mathrm{CD}^{+} \mathrm{T}$ cell regulation in $\mathrm{T}$-cell receptor transgenic mice with elevated frequencies of $\mathrm{CD}^{+} \mathrm{T}$ cells recognizing hen egg lysozyme (HEL) autoantigen expressed in islet $\beta$-cells, and found that mouse anti-islet $\mathrm{IgG}$ antibodies formed as a consequence of excessive $\mathrm{Tfh}$ cell activity, progression to diabetes was ameliorated in the absence of B cells or when the B cells could not secrete islet-specific IgG, these indicated that Tfh cell play an important role in T1DM.

\subsubsection{Other diseases}

Conlon $^{41}$ created $\mathrm{T}$ cell-deficient mice models with monoclonal populations of TCR-transgenic $\mathrm{CD}^{+} \mathrm{T}$ cells, then transplanted heart from the same species, detected the differentiation of $\mathrm{CD}^{+} \mathrm{T}$ cells transferred to the recipients by follicular localization and by acquisition of signature phenotype. They found that the transferred $\mathrm{CD} 4^{+} \mathrm{T}$ cells differentiated into Tfh cells, and thought that Tfh cells take part in the rejection of organ transplantation.

\subsection{Immunodefficiencies}

According to in vivo or in vitro experiment of $\mathrm{X}$ linked lymphoproliferative disease (XLP), ICOS produced by $\mathrm{CD} 4{ }^{+} \mathrm{T}$ cells decreased, there were something wrong with generation of the associated molecules which help for B cells, such as IL-4, IL10 , and the immunity of the patients declined. The same phenomenon existed in Hyper-IgM Syndrome (HIGM). ${ }^{42,43}$

\subsection{Infectious diseases}

In the study of hepatitis B, researchers found that the frequency of Tfh cells in patients with immuneactive (IA) CHB was significantly higher than that of immune-tolerant (IT) $\mathrm{CHB}$ and healthy controls (HC), and the percentages of Tfh cell in IA patients were positively correlated with AST. Furthermore, the percentages of Tfh cells in CHB patients were significantly higher than that of HC. Treatment with adefovir dipivoxil reduced the frequency of $\mathrm{Tfh}$ cells, the concentrations of $\mathrm{HBsAg}$ and $\mathrm{HBeAg}$, but increased the concentrations of HBsAb, HBeAb, IL2 and IFN- $\gamma$ in IA patients. Moreover, the frequency of splenic and liver Tfh cells in HBV-transgenic mice was higher than that of wild-type controls. 44

In peripheral blood of $\mathrm{HCV}$-infected patients, percentage of Tfh cells was higher than healthy controls, and statistically significant negative correlation was found between the percentage of Tfh cells and the HCV RNA load. These data suggested that Tfh cells may participate in HCV-related immune responses. ${ }^{45}$ In another study, the presence of intrahepatic Tfh cells in livers of HCV-infected patients was detected. The absolute number of liver Tfh cells progressively increased from nonresponders (NRs) to relapsers (RRs) to a maximum in sustained virological response (SVRs) patients, their amount is proportional to the ultimate likelihood of SVR, with a progressive increase from NR to RR to SVR. Quantification of Tfh cells in the liver biopsy of these patients adds useful prognostic information. 46

In the lymph node of rhesus macaques infected with SIVmac239, the progression of SIV infection was accompanied by increased numbers of well- 
delineated follicles containing GCs and Tfh cells, the density of PD-1 expression in lymph nodes progressively increased, and the rise in $\mathrm{PD}-1^{+} \mathrm{Tfh}$ cells was followed by a substantial accumulation of $\mathrm{Ki}^{+} 7^{+} \mathrm{B}$ cells within GCs. Moreover, unlike in blood, major increases in the frequency of $\mathrm{CD} 27^{+}$ memory B cells were observed in lymph nodes, indicating increased turnover of these cells which correlated with increases in total and SIV specific $\mathrm{Ab}$ levels. ${ }^{47}$

There were reports that in the patients infected with worms, T cells in the GC produced lots of IL-4, phenotype of which was alike to Tfh cells, these data indicated that $\mathrm{Tfh}$ cell probably takes part in the quick reaction against worm infection. ${ }^{27,48}$

\subsection{Tumor}

There were much similarity between angioimmunoblastic T lymphoma (AITL) cells and Tfh cells, that is, they all expressed CD4, Bcl-6, CXCR5, CD40L and PD-1, and could produce the homing molecule - CXCL13. ${ }^{49}$ Like Tfh cells, primary cutaneous $\mathrm{CD}^{+}{ }^{+}$small/medium-sized pleomorphic Tcell lymphoma (CSTCL) cells also expressed Bcl-6, CXCL13 and PD-1. ${ }^{50}$ These indicated that Tfh cell is related to development of lymphoma.

Presently, Battistella ${ }^{51}$ reported that, due to major Bcell infiltrate and CD10 positive in skin biopsy specimens, some patients were initially misdiagnosed as primary cutaneous follicle B-cell lymphoma, but rituximab-containing therapies were ineffective. In the further study, they found the biopsy specimens after treatment with rituximab showed medium to large-sized atypical T-cell skin infiltrate expressing Tfh cell markers (CD10, Bcl-6, PD-1, CXCL13 and ICOS). Finally, the diagnosis proposed for all patients was cutaneous Tfh lymphoma. According to the diagnosis, the patient with localized disease was successfully treated with radiotherapy.

\section{Prospect}

Conclusively, although the characteristic and function were identified, many questions remain unclear. What is the relation between $\mathrm{Tfh}$ cell and other $\mathrm{T}$ cell subpopulations? What are the detailed mechanisms of Tfh cell and helper B cell? Is there any interaction between Tfh cells and other immune cells? What are the functions of Tfh cells in the progression of lots of infectious diseases, autoimmune diseases and tumor? And is it possible for us to regulate $\mathrm{Tfh}$ cell that can influence the treatment of these diseases? There are many other questions also to be addressed. In near future, the researches on Tfh cells probably become a new focus to find out the possible mechanisms of immunodeficiency, infectious diseases, autoimmune diseases and tumor.

\section{References}

1. Poholek AC, Hansen K, Hernandez SG, Eto D, Chandele $\mathrm{A}$, Weinstein JS et al. In vivo regulation of Bcl6 and T follicular helper cell development. J Immunol 2010; 185(1): 313-326.

2. Baumjohann D, Okada T, Ansel KM. Cutting edge: distinct waves of BCL6 expression during T follicular helper cell development. J Immunol 2011; 187(5): 20892092.

3. Fazilleau N, Maik L, McHeyzer-WILLAMS L, McHeyzerWilliams MG. Follicular helper T cells: lineage and location. Immunity 2009; 30(3): 324-335.

4. Eto D, Lao C, DiToro D, Barnett B, Escobar TC, Kageyama R et al. IL-21 and IL-6 are cirtical for different aspects of $\mathrm{B}$ cell immunity and redundantly induce optimal follicular helper $\mathrm{CD} 4+\mathrm{T}$ cell (Tfh) differentiation. PLoS ONE 2011; 6(3): 1-11.

5. Batten M, Ramamoorthi N, Kljavin NM, Ma CS, Cox JH, Dengler HS et al. IL-27 supports germinal center function by enhancing IL-21 production and the function of T follicular helper cells[J]. J Exp Med 2010; 207(13): 2895-2906

6. Linterman MA,Beaton L, Yu D, Ramiscal RR, Srivastava M, Hogan JJ et al.IL-21 acts directly on B cells to regulates Bcl-6 expression and germinal center response. J Exp Med 2010; 207(2): 353- 363.

7. Kroenke MA, Eto D, Locci M, Cho M, Davidson T, Haddad EK et al. Bcl6 and Maf cooperate to instruct human follicular helper CD4 $\mathrm{T}$ cell differentiation. J Immunol 2012; 188(8): 3734-3744.

8. Johnston RJ, Poholek AC, DiToro D, Yusuf I, Eto D, Barnett B et al. Bcl6 and Blimp-1 are reciprocal and antagonistic regulators of $\mathrm{T}$ follicular helper cell differentiation. Science 2009; 325(5934): 1006-1010.

9. Kitano M, Moriyama S, Ando Y, Hikida M, Mori Y, Kurosaki $\mathrm{T}$ et al. Bcl6 protein expression shapes pregerminal center B cell dynamics and follicular helper $\mathrm{T}$ cell heterogeneity. Immunity 2011; 34(6): 961-972.

10. Ma CS, Avery DT, Chan A, Batten M,Bustamante J, Boisson-Dupuis S et al. Functional STAT3 deficiency 
compromises the generation of human $\mathrm{T}$ follicular helper cells. Blood 2012; 119(17): 3997-4008.

11. Nurieva RI, Podd A, Chen Y, Alekseev AM, Yu M, Qi X et al. STAT5 negatively regulates $\mathrm{T}$ follicular helper (Tfh) cell generation and function. J Biol Chem 2012; 287: 11234-11239.

12. Johnston RJ, Choi YS, Diamond JA, Yang JA, Crotty S. STAT5 is a potent negative regulator of TFH cell differentiation. J Exp Med 2012; 209(2): 243-250.

13. Danisch S, Qiu Q, Seth S, Ravens I, Dorsch M, Shibuya A et al. CD226 interaction with CD155 impacts on retention and negative selection of $\mathrm{CD} 8$ positive thymocytes as well as $\mathrm{T}$ cell differentiation to follicular helper cells in Peyer's Patches. Immunobiology 2012; Feb 17. [Epub ahead of print]

14. Good-Jacobson KL, Song E, Anderson S, Sharpe AH, Shlomchik MJ. CD80 expression on B cells regulates murine $\mathrm{T}$ follicular helper development, germinal center $\mathrm{B}$ cell survival, and plasma cell generation. J Immunol 2012; 188(9): 4217-25.

15. Ballesteros-Tato A, León B, Graf BA, Moquin A, Adams $\mathrm{PS}$, Lund $\mathrm{FE}$ et al. Interleukin-2 inhibits germinal center formation by limiting $\mathrm{T}$ follicular helper cell differentiation. Immunity 2012; 36(5): 847-856.

16. Yu D, Rao S, Tsai LM, Lee SK, He Y, Sutcliffe EL et al. The transcriptional repressor Bcl-6 directs $\mathrm{T}$ follicular helper cell lineage commitment. Immunity 2009; 31(3): 457-468.

17. Nakayamada S, Kanno Y, Takahashi H, Jankovic D, Lu KT, Johnson TA et al. Early Th1 cell differentiation is marked by a Tfh cell-like transition. Immunity 2011; 35(6): 919-931.

18. Fahey LM, Wilson EB, Elsaesser H, Fistonich CD, McGavern DB, Brooks DG. Viral persistence redirects CD4 $\mathrm{T}$ cell differentiation toward $\mathrm{T}$ follicular helper cells. J Exp Med 2011; 208(5): 987-999.

19. Zaretsky AG, Taylor JJ, King IL, Marshall FA, Mohrs M, Pearce EJ. T follicular helper cells differentiate from Th2 cells in response to helminth antigens. J Exp Med 2009; 206: 991-999.

20. Tsuji M, Komatsu N, Kawamoto S, Suzuki K, Kanagawa $\mathrm{O}$, Honjo $\mathrm{T}$ et al. Preferential generation of follicular Bhelper T cells from Foxp3 $+\mathrm{T}$ cells in gut Peyer's patches. Science 2009; 323(5920): 1488-1492.

21. Linterman MA, Pierson W, Lee SK, Kallies A, Kawamoto S, Rayner TF et al. Foxp3(+) follicular regulatory $\mathrm{T}$ cells control the germinal center response. Nat Med 2011; 17(8): 975-982.

22. Dullaers M,Li D, Xue Y, Ni L, Gayet I, Morita R et al. A $\mathrm{T}$ cell-dependent mechanism for the induction of human mucosal homing immunoglobulin A-secreting plasmablasts. Immunity 2009; 30(1): 120-129.
23. Rodríguez-Bayona B, Ramos-Amaya A, Bernal J, CamposCaro A, Brieva JA. Cutting edge: IL-21 derived from human follicular helper $\mathrm{T}$ cells acts as a survival factor for secondary lymphoid organ, but not for bone marrow, plasma cells. J Immunol 2012; 188(4): 1578-1581.

24. Choi YS, Kageyama R, Eto D, Escobar TC, Johnston RJ, Monticelli $\mathrm{L}$ et al. ICOS receptor instructs $\mathrm{T}$ follicular helper cell versus effector cell differentiation via induction of the transcriptional repressor Bcl6. Immunity 2011; 34(6): 932-946.

25. Marafioti T, Paterson JC, Ballabio E, Chott A, Natkunam $\mathrm{Y}$, Rodriguez-Justo $\mathrm{M}$ et al. The inducible T-cell costimulator molecule is expressed on subsets of $\mathrm{T}$ cells and is a new marker of lymphomas of $\mathrm{T}$ follicular helper cell-derivation. Heamatol 2010; 95(3): 432-439.

26. Julia R, Kirsten F, Martin T. Signaling pathways in $\mathrm{T}$ follicular helper cells. J Immunol 2010; 184: 6563-6568.

27. Linterman MA, Vinuesa CG. Signals that influence T follicular helper cell differentiation and function. Semin Immunopathol 2010; 32(2): 183-196.

28. Yeonseok C, Shinya T, Fuliang C, Roza I N, Gustavo J M, Seema R,Yi-Hong Wang, Hoyong L et al. Follicular regulatory $\mathrm{T}$ cells expressing Foxp3 and Bcl-6 suppress germinal center reactions. Nature Medicine 2011; 17 : 983-988.

29. Harada Y, Tanaka S, Motomura Y, Harada Y, Ohno S, Ohno $\mathrm{S}$ et al. The 3 ' enhancer CNS2 is a critical regulator of interleukin-4-mediated humoral immunity in follicular helper T cells. Immunity 2012; 36(2): 188-200.

30. Vijayanand P, Seumois G, Simpson LJ, Abdul-Wajid S, Baumjohann D, Panduro $M$ et al. Interleukin-4 production by follicular helper $\mathrm{T}$ cells requires the conserved Il4 enhancer hypersensitivity site V. Immunity 2012; 36(2): 175-187.

31. Schmitt N, Morita R, Bourdery L, Bentebibel SE, Zurawski SM, Banchereau J et al. Human dendritic cells induce the differentiation of interleukin-21-producing $\mathrm{T}$ follicular helper like cells through interleukin-12. Immunity 2009; 13(1): 158-169.

32. Goenka R, Barnett LG, Silver JS, O'Neill PJ, Hunter CA, Cancro MP et al. Cutting edge: dendritic cell-restricted antigen presentation initiates the follicular helper $\mathrm{T}$ cell program but cannot complete ultimate effector differentiation. J Immunol 2011; 187(3): 1091-1095.

33. Pelletier N, McHeyzer-Williams LJ, Wong KA, Urich E, Fazilleau N, McHeyzer-Williams MG. Plasma cells negatively regulate the folicular helper $\mathrm{T}$ cell program. Nat Immunol 2010; 11(12): 1110-1118.

34. Nurieva RI, Chung Y, Martinez GJ, Yang XO, Tanaka S, Matskevitch TD et al. Bcl6 mediates the development of $\mathrm{T}$ follicular helper cells. Science 2009; 325(5934): 10011005 . 
35. Simpson N, Gatenby PA, Wilson A, Malik S, Fulcher DA, Tangye SG et al. Expansion of circulating $\mathrm{T}$ cells resembling follicular helper $\mathrm{T}$ cells is a fixed phenotype that identifies a subset of severe systemic lupus erythematosus. Arth \& Rheu 2010; 62(1): 234-244.

36. Dong W, Zhu P, Wang Y. Follicular helper T cells in systemic lupus erythematosus: a potential therapeutic target. Autoimmun Rev 2011; 10(6): 299-304.

37. Hu YL, Metz DP, Chung J, Siu G, Zhang M.B7RP-1 blockade ameliorates autoimmunity through regulation of follicular helper T cells. J Immunol 2009; 182(3): 1421-1428.

38. Aoki N, Kido M, Iwamoto S, Nishiura H, Maruoka R, Tanaka J et al. Dysregulated generation of follicular helper $\mathrm{T}$ cells in the spleen triggers fatal autoimmune hepatitis in mice. Gastroenterology 2011; 140(4): 1322-1333.

39. Zhu C, Ma J, Liu Y, Tong J, Tian J, Chen J et al. Increased frequency of follicular helper $\mathrm{T}$ cells in patients with autoimmune thyroid disease. J Clin Endocrinol Metab 2012; 97(3): 943-950.

40. Diego GS, Stephen RD, Jennifer H, Sau KL, Charis ET, Daniel $\mathrm{YH}$ et al. Anti-islet autoantibodies trigger autoimmune diabetes in the presence of an increased frequency of islet-reactive CD4 T cells. Available at: h t t p : / / d i abetes.diabetes journals . org/ lookup/suppl/doi:10.2337/db10-1344/-/DC1.

41. Conlon TM, Saeb-Parsy K, Cole JL, Motallebzadeh R, Qureshi MS, Rehakova S et al. Germinal center alloantibody responses are mediated exclusively by indirect- pathway CD4 $\mathrm{T}$ follicular helper cells. J Immunol 2012; 188(6): 2643- 2652.

42. Rodrfguez Pinilla SM, Roncador G, Rondrfguez-Peralto JL et al. Primary cutaneous CD4+ small/medium-sized pleomorphic T-cell lymphoma expresses follicular T-cell markers. Am J Surg Pathol 2009; 33(1): 81-90.

43. Nagy N, Klein E. Deficiency of the proapoptotic SAP function in X-linked lymphoproliferative disease aggravates Epstein-Barr virus (EBV) induced mononucleosis and promotes lymphoma development. Immunol Lett 2010; 130 (1-2): 3-18.
44. Feng J, Lu L, Hua C, Qin L, Zhao P, Wang J et al. High frequency of CD4+ CXCR5+ Tfh cells in patients with immune-active chronic hepatitis B. PLoS ONE 2011; 6(7): $1-9$.

45. Feng J, Hu X, Guo H, Sun X, Wang J, Xu L et al. Patients with chronic hepatitis $\mathrm{C}$ express a high percentage of CD4(+) CXCR5(+) T follicular helper cells. J Gastroenterol 2012; doi: 10.1007/s00535-012-0568-1.

46. Tripodo C, Petta S, Guarnotta C, Pipitone R, Cabibi D, Colombo MP et al. Liver follicular helper T-cells predict the achievement of virological response following interferon-based treatment in $\mathrm{HCV}$-infected patients. Antivir Ther 2012; 17(1): 111-118.

47. Hong JJ, Amancha PK, Rogers K, Ansari AA, Villinger F. Spatial alterations between CD4(+) T follicular helper, B, and $\mathrm{CD} 8(+) \mathrm{T}$ cells during simian immunodeficiency virus infection: T/B cell homeostasis, activation, and potential mechanism for viral escape. J Immunol 2012; 188(7): 3247-3256.

48. Yusuf I, Kageyama R, Monticelli L, Johnston RJ, Ditoro $\mathrm{D}$, Hansen $\mathrm{K}$ et al. Germinal center $\mathrm{T}$ follicular helper cell IL-4 production is dependent on signaling lymphocytic activation molecule receptor (CD150). J Immunol 2010; 185(1): 190-202.

49. Rodriguez-Justo M, Attygalle AD, Munson P, Roncador G, Marafioti T, Piris MA. Angioimmunoblastic T-cell lymphoma with gyperplastic germinal centres: a neoplasia with origin in the outer zone of the germinal centre? Clinicopathological and immunohistochemical study of 10 cases with follicular T-cell markers. Modern Pathol 2009; 22: 53-761.

50. Rodriguez Pinilla SM, Roncador G, Rondrfguez-Peralto JL, Mollejo M, García JF, Montes-Moreno S et al. Primary cutaneous CD4+ small/medium-sized pleomorphic T-cell lymphoma expresses follicular T-cell markers. Am J Surg Pathol 2009; 33(1): 81-90.

51. Battistella M, Beylot-Barry M, Bachelez H, Rivet J, Vergier B, Bagot M. Primary cutaneous follicular helper T-cell lymphoma: a new subtype of cutaneous T-cell lymphoma reported in a series of 5 cases. Arch Dermatol 2012; doi: 10.1001/ archdermatol.2011.3269. 